\title{
Investigating e-wallet adoption of COVID19 intra-period among Malaysian youths': Integrated task-technology fit and technology acceptance model framework
}

\author{
Azizul Yadi Yaakop ${ }^{\mathrm{a}}$, Yee Pei Shi ${ }^{\mathrm{a}}$, Bob Foster ${ }^{\mathrm{b}}$ and Jumadil Saputra ${ }^{\mathrm{a}^{*}}$
}

${ }^{a}$ Faculty of Business, Economics and Social Development, Universiti Malaysia Terengganu, 21030 Kuala Nerus, Terengganu, Malaysia ${ }^{b}$ Faculty of Economics and Business, Universitas Informatika dan Bisnis Indonesia, Bandung, Jawa Barat 40285, Indonesia

\section{CHRONICLE ABSTRACT}

Article history:

Received: March 10, 2021

Received in revised format: April

8, 2021

Accepted: May 31, 2021

Available online: June 7, 2021

Keywords:

Task-Technology Fit (TTF)

Technology Acceptance Model

(TAM)

E-Wallet

COVID 19

Malaysian Youth's

\begin{abstract}
As embodied in Malaysia's Vision 2020, Malaysia aims to become a cashless country. Therefore, the existing statistical data indicated that the e-wallet adoption rate remains at a low percentage. It has been a barrier for Malaysia in achieving the aims to become a cashless country. The use of e-wallet was also expected to rise amidst the Covid-19 pandemic; to optimize an intervention for the Covid-19 outbreak. Thus, the current study investigates the factors that correlate with the intention to use e-wallet during the Covid-19 pandemic. This study is designed using a quantitative approach through cross-sectional data. A total of 160 Malaysian youths participated and collected by using an online survey. Further, the Task-Technology Fit (TTF) model and Technology Acceptance Model (TAM) were integrated into this study with an extended variable, namely, perceived credibility. The analysis results showed that Individual-Technology Fit, Task-Technology Fit, Perceived Usefulness, Perceived Ease of Use and Perceived Credibility were significantly correlated to Covid19 intra-period e-wallet adoption. In conclusion, a considerable theoretical contribution was demonstrated by integrating TTF-TAM and Perceived Credibility in a single integrated model. The constructs in the TTF model (i.e., Individual-technology fit and task-technology fit) has positively related to the constructs in the TAM model (i.e., perceived usefulness and perceived ease of use). This study is useful to stakeholders and provides enhanced directions to meet market needs by understanding and predicting e-wallet user's post-pandemic behavior, thereby helping service providers attract new users and retain their existing users.
\end{abstract}

\section{Introduction}

As embodied in Malaysia's Vision 2020, Malaysia aims to become a cashless country through electronic payment. Generally, the term "electronic" in the e-payment refers to the payment mode that does not involve physical cash or money (Hamid and Cheng, 2013). In Malaysia, several forms of e-payment are commonly used, including credit cards, debit cards, smartcards such as MEPS cash, Touch' n Go, and e-wallets and transactions through ATMs. According to Uddin and Akhi (2014), an electronic wallet (e-wallet) is a program or web service that provides a convenient and technologically quick method for consumers to purchase products from any person or store worldwide. The antecedents of e-wallet are developed from a concept by the founder Sam Pitroda in 1996 and the so-called "Digital Wallet" (Doan, 2014). E-wallets like physical wallets are used to store information such as credit card numbers, e-money and other information of contact number, owner identity, shipping, or billing address when it can be found or obtained from e-commerce sites (Junadi, 2015). In the first quarter of 2020, the use of contactless payments, especially the adoption of e-wallets, are on the rise in the intra-period coronavirus outbreak and Movement Control Orders (MCO) in Malaysia (The Straits Times, 2020, April 27). The public felt safer and

* Corresponding author. Tel.: +60176939109

E-mail address: jumadil.saputra@umt.edu.my (J. Saputra)

(C) 2021 by the authors; licensee Growing Science, Canada. doi: $10.5267 /$ j.ijdns.2021.6.004 
more hygienic for them to use e-wallet instead of banknotes to exercise contactless transactions and social distancing whenever payments are made. During the outbreak, the government of Malaysia has introduced several incentives to cope with the pandemic, one of which, as announced by Prime Minister Malaysia Tan Sri Muhyiddin Yassin, was the RM50 digital initiative under the "Penjana Economic Recovery Plan" (New Straits Time, 2020, June 5). This e-wallet credit is worth RM750 million and has benefited about 15 million Malaysians.

By following the Malaysia Central Bank's Financial Sector Blueprint for 2011 to 2020, Malaysia stands to gain about 1 per cent in cost savings to our GDP annually by switching fully to e-payments processes and becoming a cashless society. The mobile payment transaction volume had increased twenty-fold to over 34 million transactions in 2018 from just below 2 million transactions in 2017. However, based on Nielsen's survey report in January this year, the overall adoption of e-wallet remains low at only 8 per cent because of security risk concerns to use a technology system (Nielsen Malaysia, 2019). Based on a report last year by The Star (2019, June 19), cashless payments make up about 20 per cent of total payments in the country, with only half of that involving e-wallets. The low adoption rate in using e-wallets by Malaysian has obstructed achieving the Vision 2020 Malaysia to become a cashless country. However, the adoption of e-wallet in Malaysia has risen rapidly in the intra-period Covid10 pandemic. There was an overwhelming response from the Malaysians` reaction to the ewallet credit as 700,000 registrations at once in a minute in response to the government RM50 digital incentive (The Star, 2020, June 9). Besides encouraging safe and contactless payment during the pandemic period of COVID-19, it also has spurred the adoption of e-wallet among Malaysians. It thus brings Malaysia to move into a cashless country. The CEO of Touch's N Go Sdn Bhd, Syahrunizam Samsudin, said that the e-wallet market depended on the demographics and age group, with those between 18 and 25 having an average of five e-wallets to maximize the benefits.

In comparison, those above 35 tend to focus on only one or two e-wallets as it was more convenient (New Straits Times, 2019, July 5). According to the Nielsen Payment Landscape Report, awareness of e-wallet in Malaysia is high (88 per cent) as many providers have entered the sector. Anil Antony, Executive Director Consumer Insights of Nielsen Malaysia, said that Malaysia's younger and more tech-savvy population, which may not have sufficient credit history to qualify for a card, could be more open to using e-wallets for everyday expenses due to the convenience factor (Nielsen Malaysia, 2019, January 3). Due to this characterization of e-wallet users, the current study examines Malaysian youths' perspective during Covid19 intraperiod e-wallet adoption.

Currently, the adoption of e-wallets is heavily based on promotions, causing many consumers to download e-wallet apps without necessarily using them. How can e-wallet providers encourage continuous, sustainable usage of e-wallets among existing users post-pandemic? To spur the cashless economy and drive increased e-wallet practice adoption, the cashless payment providers need to pay attention to understanding the market demand. Can the integration of the TTF-TAM framework answer this question? Some research questions guided the study to achieve the objectives. Thus, this research's general purpose was to examine the integration of the TTF-TAM framework from the current scenario of Malaysian youths Covid19 intraperiod e-wallet adoption.

\section{Literature Review}

This section reviews several studies on Task-Technology Fit (TTF), Technology Acceptance Model and Perceived Credibility.

\subsection{Task-Technology Fit (TTF) Model}

The TTF model is a commonly used model to evaluate how information technology leads to a performance by assessing the match between task and technology characteristics (Wu \& Chen, 2017). The original TTF model assumes that users tend to use information technology to obtain benefits, such as improved job performance (Lee et al., 2007). Also, TTF is related to the degree to which the technology meets the task-related requirements, and the concept is conceptually related to the TAM structure that user-perceived usefulness (Yu \& Yu, 2010). The combination of TAM and TTF models may give a robust explanation for using information technology and mobile applications in a pandemic scenario. This interpretation's accuracy is higher than that only based on TAM or TTF models (Klopping \& McKinney, 2004). Individual-Technology Fit refers to individual interactions with information systems that are often intertwined with their technical adaptation behavior (Yu and $\mathrm{Yu}, 2010)$. Besides, Task-Technology Fit (TTF) is how the capabilities of the information system match the tasks that the consumer must perform (Goodhue, Klein, and March 2000). Empirical studies have suggested that both ITF and TTF positively affect PEOU and PU (Wu \& Chen, 2017; Baabdullah et al., 2019). Further research is needed to determine the correlation between the TTF model [i.e., Individual-Technology Fit (ITF) and Task-Technology Fit (TTF)] on Perceived Usefulness (PU) and Perceived Ease of Use (PEOU) of e-wallet during this period of Covid19 cataclysm. Hence, the following set of hypotheses is proposed in this research:

$\mathbf{H}_{1}$ : Individual-Technology Fit (ITF) has a positive correlation with the perceived usefulness (PU) of e-wallet Covid19 intraperiod adoption. 
$\mathbf{H}_{2}$ : Individual-Technology Fit (ITF) has a positive correlation with the perceived ease of use (PEOU) of e-wallet Covid19 intra-period adoption.

$\mathbf{H}_{3}$ : Task-Technology Fit (TTF) has a positive correlation with the perceived usefulness (PU) of e-wallet Covid19 intra-period adoption.

H4: Task-Technology Fit (TTF) has a positive correlation with the perceived ease of use (PEOU) of e-wallet Covid19 intraperiod adoption.

\subsection{Technology Acceptance Model (TAM)}

Technology Acceptance Model (TAM) was adopted to identify factors affecting the students` intention to use the e-wallet. Davis (1989) defined TAM as a well-established model based on the psychological interaction of a user with technology, and it addresses how users accept and use information technology. Acceptance research (Davis, 1986, 1989; Davis, Bagozzi, \& Warshaw, 1989) suggests that Perceived Ease of Use and Perceived Usefulness are the two key determinants that influence the acceptance and intention to use information technology. First, "people tend to use or not use an application to the extent they believe it will help them perform their job better" (Davis, 1989). This statement refers to "perceived usefulness". Second, people perceive that if the technology is too hard to use, they tend not to adopt and not to use it even though they believe that the technology is useful. This notion refers to this second variable as "perceived ease of use". In line with the previous TAM studies (Kucukusta et al., 2015; Kim \& Garrison, 2009), the results confirmed that Perceived Ease of Use and Perceived Usefulness are the primary factors in assessing behavioral intentions toward technology adoption. TAM is used in this study for its predictive ability in studies involving students (Kiraz \& Ozdemir, 2006; Teo, 2009). The researcher has also added a new and valid construct, i.e., perceived credibility, into the model to understand the technology's acceptance. In this research, the model consists of five constructs which are individual-technology fit, task-technology fit, perceived ease of use, perceived usefulness, and perceived credibility. TAM used by the researcher as a guideline to complete the research. Numerous researchers have used various constructs to relate the dependent variables in TAM. This study examines the correlation between Perceived Usefulness and Malaysian Youths' intention to use an e-wallet. Hence, the following hypothesis is proposed in this research:

\section{H5: Perceived usefulness (PU) has a positive correlation with the intention of e-wallet Covid19 intra-period adoption.}

As far as the TAM framework is concerned, this study also attempts to identify the correlation between Perceived Ease of Use and e-wallet adoption intention among the youths during this pandemic situation. Hence, another hypothesis has designed for this research:

\section{H6: Perceived ease of use (PEOU) has a positive correlation with the intention of e-wallet Covid19 intra-period adoption.}

\subsection{Perceived Credibility $(P C)$}

Perceived credibility defined as the extent to which a person believes that using mobile service will be free of security and privacy threats (Wang et al. 2003). It was considered redundant with perceived security and privacy. Also, Mun, Khalid and Nadarajah (2017) define perceived credibility as the consumers' judgment on mobile payment services' privacy and security issues. There are two key elements in perceived credibility: security and privacy (Lu et al., 2003). Yenisey et al. (2005) defined perceived security and privacy as the degree to which a customer believes that using a mobile payment procedure will be secure. The security level of the transaction is considered a key issue and core to develop e-commerce (Udo, 2001). Fang et al. (2014) stated that customers want their personal information and identity to be kept confidential because they are afraid of their information being misused for online fraud. Previous results present a significant direct relationship between perceived credibility and behavioral intention (Lin \& Wang, 2005; Shin, 2009). Perceived credibility found to have a significant positive influence on the behavioral intentions to use online banking (Wang et al., 2003; Luarn \& Lin, 2005). Their findings indicated that the perceived credibility has more impact than the perceived ease of use and perceived usefulness on behavioral intention to use. Mobile banking is also considered as one of the mobile payment services like an e-wallet. Consequently, perceived credibility is used as a TAM construct to reflect the security and privacy concerns in accepting e-wallet. As an extension to the TAM framework, Perceived Credibility is hypothesized to correlate positively with Malaysian youths' intention to use ewallet during this pandemic intra-period. Hence, the following hypothesis is proposed in this research:

\section{H7: Perceived credibility has a positive correlation with the intention of e-wallet Covid19 intra-period adoption.}




\section{Methodology}

This research is quantitative; in the effort to quantify the research problem and establish the mechanisms through which one or more variables may relate to another variable. In general, quantitative research involves a sizable representative sample and a formalized procedure for gathering data (Taheri et al., 2015; Burns \& Bush, 2014). Specifically, this study aims at determining variable correlation for Malaysian youths' Covid19 intra-period e-wallet adoption. An online survey via Google form was used to gather data from the respondents. Non-probability sampling was chosen during a pandemic situation. The chances (probability) of selecting members from the population into the sample are unknown (Burns \& Bush, 2014). The recommendation for a minimum sample size of 100-200 observations is probably based on the argument that a correlation coefficient becomes an adequate estimator of the population correlation coefficient when sample sizes reach this level (Hair et al., 1979; Hair et al., 1998; Hair et al., 2010). Hence, the researcher decided to use a sample size of 160 respondents based on the similar research of intention to use e-wallet conducted by $\mathrm{Tu}$ (2019). The online questionnaire was designed for all the question items and was set using the five-point Likert scale, ranging from 1 (strongly disagree) to 5 (strongly agree). It can help the researchers to identify the correlation between independent variables and dependent variables. In this research, a total of 160 respondents were collected using the questionnaire that was analyzed by assisting the statistical software, namely SPSS-22. Descriptive and correlation analyses were applied to analyze each section of the data collected to prove the research objectives and hypotheses:

\section{Results and Discussion}

Before examining the correlation analysis, the first section will present the respondents' distribution in this study. The result of the respondent's distribution.

Table 1

Demography Profile of Respondent's

\begin{tabular}{|c|c|c|c|}
\hline \multicolumn{2}{|c|}{ Demographic } & \multirow{2}{*}{$\begin{array}{c}\text { Frequencies } \\
69\end{array}$} & \multirow{2}{*}{$\begin{array}{c}\text { Percentage (\%) } \\
43.1\end{array}$} \\
\hline & $20-22$ & & \\
\hline \multirow[t]{2}{*}{ Age } & $23-25$ & 88 & 55.0 \\
\hline & 26 or above & 3 & 1.9 \\
\hline \multirow[t]{2}{*}{ Gender } & Male & 45 & 28.1 \\
\hline & Female & 115 & 71.9 \\
\hline \multirow[t]{4}{*}{ Race } & Malay & 94 & 58.8 \\
\hline & Chinese & 56 & 35.0 \\
\hline & Indian & 3 & 1.9 \\
\hline & Others & 7 & 4.4 \\
\hline \multirow[t]{3}{*}{ Place } & Urban & 72 & 45.0 \\
\hline & Suburban & 39 & 24.4 \\
\hline & Rural & 49 & 30.6 \\
\hline \multirow[t]{3}{*}{ Education } & STPM & 95 & 59.4 \\
\hline & Foundation/Matriculation & 39 & 24.4 \\
\hline & Diploma & 26 & 16.3 \\
\hline \multirow[t]{4}{*}{ Faculty } & FPEPS & 80 & 50.0 \\
\hline & FSSM & 26 & 16.3 \\
\hline & FTKKI & 17 & 10.6 \\
\hline & FPSM & 37 & 23.1 \\
\hline \multirow[t]{4}{*}{ Year } & $1^{\text {st }}$ & 19 & 11.9 \\
\hline & $2^{\text {nd }}$ & 18 & 11.3 \\
\hline & $3^{\text {rd }}$ & 114 & 71.3 \\
\hline & $4^{\text {th }}$ & 9 & 5.6 \\
\hline
\end{tabular}

Table 1 displays the results of the demographic profile. The above table showed that most respondents aged 23 to 25 years old, as much as 88 or 55 per cent. Further, most respondents who have participated in this study are female, e.g., 115 or 71.9 per cent, and all respondents are of Malay race. The respondents were distributed mainly from the urban area, as much as 72 or 45 per cent. The respondents have received the STPM certificate for the education level, as big as 95 or 59 per cent. Also, most of the respondents are faculty (FPEPS) and $3^{\text {rd }}$-year students. Having that, for ensuring the data represents the population. We employ the normality test. The result showed that all the Sig. values in Shapiro-Wilk were 0.000 . It indicated normality violation, and the data were not normally distributed (Pallant, 2013). Since the normality result suggested that this research sample data was not normally distributed, a non-parametric test has opted for data analysis. The non-parametric test is often called distribution-free tests and can be used instead of their parametric equivalent (Marshall and Samuels, 2017). The researcher has used Spearman's rho as a non-parametric approach to testing the correlation between two variables for correlation analysis. 
Table 2

The result of the matrix correlation coefficient using Spearman's Rho $(\mathrm{N}=160)$.

\begin{tabular}{|c|c|c|c|c|c|c|c|}
\hline & & ITF & TTF & $\mathrm{PU}$ & PEOU & $\mathrm{PC}$ & ITU \\
\hline \multirow[t]{6}{*}{ Spearman's rho } & ITF & 1.000 & & 0.650 & 0.399 & & \\
\hline & TTF & & 1.000 & 0.706 & 0.673 & & \\
\hline & PU & & & 1.000 & & & 0.737 \\
\hline & PEOU & & & & 1.000 & & 0.456 \\
\hline & $\mathrm{PC}$ & & & & & 1.000 & 0.469 \\
\hline & ITU & & & & & & 1.000 \\
\hline
\end{tabular}

Note: All correlations are significant at the 0.01 level (2-tailed)

Table 2 captures the result of the matrix correlation coefficient using Spearman's Rho. Using the correlation analysis result, this study found that ITF - PU and ITF-PEOU have significantly correlated with the correlation coefficient's value is 0.650 or 65 per cent and 0.399 or 39.9 per cent. It means that ITF has 65 percent correlation with PU is 65 percent and vice versa. Also, the ITF has correlated with PEOU as much as 39.9 percent and vice versa. For TTF correlation with PU and PEOU, this study found that the variables significantly correlated with the value of correlation coefficient is 0.706 or 70.6 percent and 0.673 or 67.3 per cent. Also, by following the proposed hypotheses, we test the correlation of PU, PEOU, and PC with ITU. The correlation analysis result indicated that all variables have significantly correlated with the correlation coefficient is 0.737 , 0.456 and 0.469 . It means that PU, PEOU, and PC have correlated with ITU is 73.7, 45.6 and 46.9 percent and vice versa.

Table 3

The results and summary of the proposed hypotheses

\begin{tabular}{llccc}
\hline \multicolumn{2}{c}{ Hypothesis } & Correlation Coefficient & Level of Correlation & Decision \\
\hline $\mathbf{H}_{\mathbf{1}}$ & ITF $\leftarrow \rightarrow$ PU & 0.650 & Large & Supported \\
$\mathbf{H}_{\mathbf{2}}$ & ITF $\leftarrow \rightarrow$ PEOU & 0.399 & Medium & Supported \\
$\mathbf{H}_{3}$ & TTF $\leftarrow \rightarrow$ PU & 0.706 & Large & Supported \\
$\mathbf{H}_{4}$ & TTF $\leftarrow \rightarrow$ PEOU & 0.673 & Large & Supported \\
$\mathbf{H}_{5}$ & PU $\leftarrow \rightarrow$ ITU & 0.737 & Large & Supported \\
$\mathbf{H}_{6}$ & PEOU $\leftarrow \rightarrow$ ITU & 0.456 & Medium & Supported \\
$\mathbf{H}_{7}$ & PC $\leftarrow \rightarrow$ ITU & 0.469 & Medium & Supported \\
\hline
\end{tabular}

Table 3 describes the result and summary of the proposed hypotheses. The above table indicated that all proposed hypotheses are supported ( $\mathrm{H} 1$ to $\mathrm{H} 7$ ). Further, we also present the correlation level using category measurement (e.g. small, medium and large). The result of Spearman's rho correlation test showed that the correlation between (ITFßàPEOU), (PEOU ßà ITU) and (PC ß àITU) have been categorized as medium. Then, the correlation between (ITFßàPU), (TTF ßà PU), (TTFß àPEOU), and (PU BàITU) have been categorized as large. In conclusion, all the hypotheses are supported. The results also indicated the TTF model correlated with the TAM model, and the extended variable of Perceived Credibility has a positive correlation to Covid19 intra-period e-wallet adoption. It is consistent with past research on integrating these two models as the research framework.

\section{Conclusions}

A considerable theoretical contribution was demonstrated by integrating TTF-TAM and Perceived Credibility in a single integrated model. The research results have indicated the constructs in the TTF model (i.e. Individual-technology fit and tasktechnology fit) has positively related to the constructs in the TAM model (i.e. perceived usefulness and perceived ease of use). It brings a mean of a significant correlation between the TTF model and the TAM model. It can also be used for further study as it is worth empirical research. Combining the TTF model and TAM model has made it possible for a developed integrated model as the main conceptual framework for future reference. This research has provided a theoretical contribution and the use of this integrated model. It would provide a better understanding of consumers' technological adoption amidst pandemic and its continuance use post-pandemic. The cashless payment providers, particularly e-wallet providers, should understand the needs and wants of the e-wallet users amidst the Covid-19 pandemic within Malaysia by determining their behavior through this research. Through this study, e-wallet providers need to comprehend what they can do to enhance e-wallet applications' features and alleviate the barriers to use an e-wallet, such as the bad appearance of an e-wallet or less useful functions. They ought to upgrade their service system with the latest technology as local users have become technologically savvy. The results can indirectly help e-wallet providers to attract new users and retain the existing ones by acknowledging consumers' full understanding of e-wallet usefulness, including consumers' understanding of e-wallet ease of use. E-wallet providers may need to simplify the applications for the users further. Moreover, the research can help foster the adoption of e-wallet and spur the cashless payment mode in the long run. The research can provide an insight into the mobile telecommunication industry, marketers, decision-maker and academics on the factors that encourage users to use mobile payment, especially e-wallet. It can facilitate the adoption of e-wallet after the improvement made by e-wallet providers. Thus, it can promote cashless payment mode development in the long run and finally aid in achieving a cashless country. Future studies are recommended to 
ascertain issues about the practice of e-wallet, especially in the context of Malaysia consumers preferences. The current research scope is too wide and generic in exploring the current trend in the Malaysian consumerism setting. Presently, the three most popular e-wallet providers are Touch 'n Go e-wallet, Boost and GrabPay. As the e-wallet issuers and providers increase continuously, there is a need to investigate the behavioral factors to use e-wallet based on certain types or brands of e-wallet providers. Stiff competition forces these providers to understand their sustainable competitive strengths from the consumers' viewpoint. Users' experience with the brand might be different at any point of transactions or in many situations.

\section{References}

Baabdullah, A. M., Alalwan, A. A., Rana, N. P., Patil, P., \& Dwivedi, Y. K. (2019). An integrated model for m-banking adoption in Saudi Arabia. International Journal of Bank Marketing, 37(2), 452-478.

Bank Negara Malaysia. (2019). List of Non-bank E-money issuers. Retrieved from Bank Negara Malaysia:

http://www.bnm.gov.my/index.php?ch=ps\&pg=ps_nonbank_emoney

Bank Negara Malaysia. (2019). List of Regulatees. Retrieved from Bank Negara Malaysia: http://www.bnm.gov.my/index.php?ch=ps\&pg=ps_regulatees

Bank Negara Malaysia. (2019, October 11). The 2020 Budget Speech. Retrieved from Bank Negara Malaysia:

http://www.bnm.gov.my/index.php?ch=en_announcement\&pg=en_announcement\&ac $=742$

Burns, A. C., \& Bush, R. F. (2014). Marketing Research (7th ed.). Pearson Education.

Burns, N., \& Groves, K. (1997). Practice of nursing research. Philadelphia, PA: WB Saunders company.

Business Dictionary. (2019). Definition of Data Analysis. Retrieved from Business Dictionary: http://www.businessdictionary.com/definition/data-analysis.html

Davis, F. D. (1986). Technology acceptance model for empirically testing new end-user information systems: Theory and results. Doctoral Dissertation, Massachusetts Institute of Technology: Cambridge, MA.

Davis, F. D. (1989). Perceived usefulness, perceived ease of use and user acceptance of information technology. MIS Quarterly, 13(3), 319-340.

Davis, F. D. (1993). User acceptance of information technology: System characteristics, user perceptions and behavioral impacts. International Journal of Man Machine Studies, 38(3), 475-487.

Davis, F. D., Bagozzi, R., \& Warshaw, P. (1989). User acceptance of computer technology: A comparison of two theoretical models. Management Science, 35(8).

Doan, N. (2014). Consumer adoption in mobile wallet: a study of consumers in Finland.

Fang, Y., Qureshi, I., Sun, H., McCole, P., Ramsey, E., \& Lim, K. H. (2014). Trust, satisfaction, and online repurchase intention: The moderating role of perceived effectiveness of e-commerce institutional mechanisms. Mis Quarterly, 38(2).

Goodhue, D. L., Klein, B. D., \& March, S. T. (2000). User evaluations of IS as surrogates for objective performance. Information \& Management, 38(2), 87-101.

Hair, J. F., Anderson, R. E., Tatham, R. L., \& Grablowsky, B. J. (1979). Multivariate data analysis. Tulsa, OK: Pipe Books.

Hair, J.F. Jr., Black, W.C., Babin, B.J., Anderson, R.E., \& Tatham, R.L. (1998). Multvariate data analysis (Vol. 5, No. 3, pp. 207-219). Upper Saddle River, NJ: Prentice hall.

Hair, J. F. Jr., Babin, B.J., Money, A. H., \& Samouel, P. (2003). Essential of business research methods. John Wiley \& Sons: United States of America.

Hair, J.F. Jr., Black, W.C., Babin, B.J., Anderson, R.E. (2010). Multvariate data analysis: A Global Perspective. 7th Edition. Pearson.

Hamid, N. R., \& Cheng, A. Y. (2013). A risk perception analysis on the use of electronic payment systems by young adult. Order, 6(8.4), 6-7.

Junadi, S. (2015). A model of factors influencing consumer's intention to use e-payment system in Indonesia. Procedia Computer Science, 59, 214-220.

Kim, T., Suh, Y. K., Lee, G., \& Choi, B. G. (2010). Modelling roles of task-technology fit and self-efficacy in hotel employees' usage behaviours of hotel information systems. International Journal of Tourism Research, 12(6), 709-725.

Kiraz, E. \& Ozdemir, D. (2006). The relationship between educational ideologies and technology acceptance in pre-service teachers. Educational Technology and Society, 9(2), 152-165. http://www.ifets.info/journals/9_2/13.pdf

Klopping, I.M. \& McKinney, E. (2004). Extending the technology acceptance model and the task technology fit model to consumer e-commerce. Information Technology, Learning, and Performance Journal, 22(1), 35-47.

Kucukusta, D., Law, R., Besbes, A., \& Legohérel, P. (2015). Re-examining perceived usefulness and ease of use in online booking: the case of Hong Kong online users. International Journal of Contemporary Hospitality Management, 27(2).

Lee, C.C., Cheng, H.K., \& Cheng, H.H. (2007). An empirical study of mobile commerce in insurance industry: task-technology fit and individual differences. Decision Support Systems, 43(1), 95-110.

Lin, H. H., \& Wang, Y. S. (2005, July). Predicting consumer intention to use mobile commerce in Taiwan. In International Conference on Mobile Business (ICMB'05) (pp. 406-412).

Luarn, P., \& Lin, H. H. (2005). Toward an understanding of the behavioral intention to use mobile banking. Computers in Human Behavior, 21(6), 873-891.

Marshall, E. \& Samuels, P. (2017). Statstutor community project. Checking normality for parametric tests in SPSS. Retrieved from Statstutor website: www.statstutor.ac.uk.

Ministry of Finance Malaysia. (2017). Monetary and Financial Developments. Retrieved from Ministry of Finance Malaysia: 
https://www.treasury.gov.my/pdf/economy/er/1718/chapter5.pdf

Mun, Y. P., Khalid, H., \& Nadarajah, D. (2017). Millennials' perception on mobile payment services in Malaysia. Procedia Computer Science, 124, 397-404.

New Straits Times. (2017, November 15). UTM to turn into a cashless campus. Retrieved from New Straits Times:

https://www.nst.com.my/education/2017/11/303402/utm-turn-cashless-campus

News Straits Times. (2019, March 26). LGE: Malaysia well on its way to become a cashless society. Retrieved from News Straits Times:

https://www.nst.com.my/business/2019/03/473117/lge-malaysia-well-its-way-become-cashless-society

New Straits Times. (2019, May 15). Cashless in UUM with kiplePay. Retrieved from New Straits Times:

https://www.nst.com.my/education/2019/05/488606/cashless-uum-kiplepay

New Straits Times. (2019, July 5). E-Wallet providers need to work together to educate consumers. Retrieved from New Straits Times:

https://www.nst.com.my/news/nation/2019/07/501764/e-wallet-providers-need-work-together-educate-consumers

New Straits Times. (2020, June 5). RM50 e-wallet credit to encourage contactless payment. Retrieved from New Straits Times:

https://www.nst.com.my/news/nation/2020/06/598242/rm50-e-wallet-credit-encourage-contactless-payment

Nielsen Malaysia. (2019, January 3). Cash or cashless? Malaysia's shifting payment landscape. Retrieved from Nielsen Malaysia:

https://www.nielsen.com/my/en/insights/article/2019/cash-or-cashless-malaysias-shifting-payment-landscape/

Ozturk, A. B. (2016). Customer acceptance of cashless payment systems in the hospitality industry. International Journal of Contemporary Hospitality Management, 28(4), 801-817.

Pallant, J. (2013). SPSS survival manual. $3^{\text {rd }}$ ed. McGraw-Hill Education (UK).

RAM Rating Services Berhad. (2019, May 21). Rise of mobile payment not a threat to Malaysian banks. Retrieved from RAM Rating Services Berhad: https://www.ram.com.my/pressrelease/?prviewid=4970

Shin, D. H. (2009). Towards an understanding of the consumer acceptance of mobile wallet. Computers in Human Behavior, 25(6), 1343-1354.

Smart, K. L., \& Cappel, J. J. (2006). Students' perceptions of online learning: A comparative study. Journal of Information Technology Education: Research, 5(1), 201-219.

Statista Research (2020, April 20). Malaysia: E-commerce payment methods 2019. Retrieved from statista website:

https:/www.statista.com/statistics/895540/e-commerce-payment-methods-malaysia/

Taheri, B., Porter, C., Valantasis-Kanellos, N., \& König, C. (2015). Quantitative data gathering techniques. O'Gorman, K. \& MacIntosh, R.(eds.), Research Methods for Business and Management.

Teo, T. (2009). Modelling technology acceptance in education: A study of pre-service teachers. Computers \& Education, $52(2), 302-312$

http://dx.doi.org/10.1016/j.compedu.2008.08.006

The Malaysian Reserve. (2018, December 21). E-wallet users see rapid growth in M'sia. Retrieved from The Malaysian Reserve:

https://themalaysianreserve.com/2018/12/21/e-wallet-users-see-rapid-growth-in-msia/

The Star Online. (2018, January 23). UiTM to go cashless and cardless. Retrieved from The Star Online:

https://www.thestar.com.my/news/nation/2018/01/23/uitm-to-go-cashless-and-cardless-boost-mobile-payment-app-to-beused-for-all-oncampus-transactions/

The Star Online. (2019, March 27). No cash no problem. Retrieved from The Star Online: https://www.thestar.com.my/business/business-news/2019/03/27/no-cash-no-problem

The Star Online. (2019, June 19). CEO: Time for e-wallet environment to consolidate. Retrieved from The Star Online:

https://www.thestar.com.my/business/business-news/2019/06/19/ceo-time-for-ewallet-environment-to-consolidate\#s5tvQvQYH2qKZMvv.99

The Star Online. (2020, January 15). E-wallets offer freebies on top of RM30 e-Tunai initiative. Retrieved from The Star Online:

https://www.thestar.com.my/tech/tech-news/2020/01/15/e-wallets-offer-freebies-on-top-of-e-tunai-rm30-handout The Star Online. (2020, January 15). Towards a cashless society with e-Tunai Rakyat. Retrieved from The Star Online: https://www.thestar.com.my/business/business-news/2020/01/15/towards-a-cashless-society-with-e-tunai-rakyat The Star Online. (2020, January 21). Lim: Three million people signed up for e-Tunai Rakyat. Retrieved from The Star Online: https://www.thestar.com.my/news/nation/2020/01/21/lim-three-million-people-signed-up-for--e-tunai-rakyat The Star Online. (2020, June 9). MySejahtera mobile app flooded by 700,000 registrations. Retrieved from The Star Online: https://www.thestar.com.my/news/nation/2020/06/09/mysejahtera-mobile-app-crashed-by-700000-registrations

The Straits Times. (2020, April 27). Coronavirus pandemic has steepened adoption curve of e-wallets in Malaysia. Retrieved from The Straits Times Online:

https://www.straitstimes.com/asia/se-asia/coronavirus-pandemic-has-steepened-adoption-curve-of-e-wallets-in-malaysia Topuniversities.com (2019). Universiti Malaysia Terengganu (UMT). Retrieved from https://www.topuniversities.com/universities/universiti-malaysia-terengganu-umt

Uddin, M. S., \& Akhi, A. Y. (2014). E-wallet system for Bangladesh an electronic payment system. International Journal of Modeling and Optimization, 4(3), 216. 
Udo, G. J. (2001). Privacy and security concerns as major barriers for e-commerce: a survey study. Information Management \& Computer Security, 9(4), 165-174.

Wang, Y. S., Wang, Y. M., Lin, H. H., \& Tang, T. I. (2003). Determinants of user acceptance of Internet banking: an empirical study. International Journal of Service Industry Management, 14(5), 501-519.

Wu, B., \& Chen, X. (2017). Continuance intention to use MOOCs: Integrating the technology acceptance model (TAM) and task technology fit (TTF) model. Computers in Human Behavior, 67, 221-232.

Yenisey, M. M., Ozok, A. A., \& Salvendy, G. (2005). Perceived security determinants in e-commerce among Turkish university students. Behaviour \& Information Technology, 24(4), 259-274.

Yu, T. K., \& Yu, T. Y. (2010). Modeling the factors that affect individuals' utilization of online learning systems: An empirical study combining the task technology fit model with the theory of planned behavior. British Journal of Educational Technology, 41(6), 1003e1017. http://dx.doi.org/10.1111/j.1467-8535.2010.01054.x.

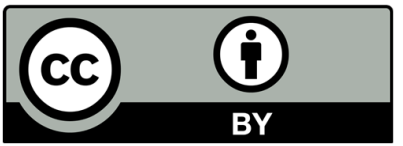

(C) 2021 by the authors; licensee Growing Science, Canada. This is an open access article distributed under the terms and conditions of the Creative Commons Attribution (CC-BY) license (http://creativecommons.org/licenses/by/4.0/). 